\title{
An update on the ecological distribution of the Ixodidae ticks in Zimbabwe
}

\author{
*Marvelous Sungirai ${ }^{1,2}$, Maxime Madder ${ }^{1,3}$, Doreen Zandile Moyo ${ }^{4}$, Patrick De Clercq ${ }^{5}$, Emmanuel \\ $\mathrm{Nji} \mathrm{Abatih}^{6}$ \\ ${ }^{1}$ Insititute of Tropical Medicine, Department of Biomedical Sciences, Unit of Veterinary Entomology, Nationalestraat 155, \\ 2000 Antwerp, Belgium \\ ${ }^{2}$ Midlands State University, Department of Livestock and Wildlife Management, 1 Senga Road, P. Bag 9055 Gweru, \\ Zimbabwe \\ ${ }^{3}$ Department of Veterinary Tropical Diseases, Faculty of Veterinary Science, University of Pretoria,Private Bag X04, \\ Onderstepoort 0110, South Africa \\ ${ }^{4}$ Midlands State University, Department of Biological Sciences, 1 Senga Road, P. Bag 9055 Gweru, Zimbabwe \\ ${ }^{5}$ Ghent University, Dept. Crop Protection, Coupure Links 653, B-9000 Gent, Belgium \\ ${ }^{6}$ Insititute of Tropical Medicine, Department of Biomedical Sciences, Unit of Veterinary Biostatistics and Epidemiology, \\ Nationalestraat 155, 2000 Antwerp, Belgium \\ *Corresponding author: MSungirai@itg.be, +263-54-260404-Ext 2215
}

\section{Abstract}

In total 7567 were collected from 121 dip tanks in 12 districts representative of Zimbabwe's five ecological regions between September 2013 and May 2014. Based on morphological traits four genera and 13 species of ticks were identified. Amblyomma hebraeum (60.3\%), Rhipicephalus microplus (58.7\%), Rhipicephalus decoloratus (47.1\%), Rhipicephalus appendiculatus (56.2\%), Rhipicephalus evertsi evertsi (67.8\%), Rhipicephalus (near) punctatus (13.2\%), Hyalomma truncatum (38\%) and Hyalomma rufipes (46.3\%) were found in all the ecological regions of the country. Amblyomma variegatum and Rhipicephalus compositus $(0.8 \%)$ were only found in the north central part of the country while Rhipicephalus simus (5\%) had a sparse distribution. The Haemaphysalis leachi group (1.7\%) and Rhipicephalus sanguineus (1.7\%) were found whenever dogs were sampled suggesting these could be widespread throughout the country. The study confirmed the continued limited distribution of Amblyomma variegatum (3.3\%) in the north central parts of the country, whereas A. hebraeum was found to have a wide distribution also encroaching areas of high rainfall and lower temperatures where it was not previously recorded. A parapatric relationship existed between these two Amblyomma species. Rhipicephalus appendiculatus was also widely distributed although its presence was dominant in the cooler and wetter parts of the country. The traditionally held view that Hyalomma species and R. evertsi evertsi can survive well under diverse conditions is upheld in this study. Rhipicephalus microplus was also present in dry regions but its adaptability to these regions requires further investigation. 
Keyword: Ticks, ecology, distribution, Zimbabwe

\section{Introduction}

Ticks are the major veterinary pests parasitizing livestock in Zimbabwe with at least $60 \%$ of all livestock mortalities being related to tick-borne and tick-related diseases (Department of Veterinary Service, 2013, unpublished). Globally 867 tick species have been described with $10 \%$ of these being of veterinary importance (Jongejan and Uilenberg, 2004). In Southern Africa about 90 species of ticks have been described, 35 of these being associated with domestic animals and 15 being of economic importance (Spickett et al., 2011; Walker, 1991). The major factors that affect distribution of ticks are environmental suitability (Cumming, 1999) and the presence of suitable hosts (Tonnesen et al., 2004). Previous studies have attempted to describe and map the distribution of ticks in Zimbabwe (Mason and Norval, 1980; Peter et al., 1998). However there is a need to continually update such information due to spatial and temporal changes which might influence tick distribution. Over the past fifteen years, the Zimbabwean government has implemented a land reform programme which has resulted in changes in land use patterns. This will eventually have a cascading effect also on tick distribution as through livestock movements ticks would migrate to other areas in which they were not known to occur and if the environment is suitable they may become established in those localities (Léger et al., 2013). The Boophilus ticks commonly referred to as the blue ticks are ticks which are particularly affected by such movements, because as one-host ticks they remain for a long time on the animal from larva to adult, with females dropping off as engorged ticks to lay eggs on the ground and hence the chances of them moving with the animal are high. Recent studies have focused on the relationship that exists between this sub-group of the Rhipicephalus species and results have indicated that Rhipicephalus microplus is displacing other ticks of the same genus in West Africa, South Africa, Tanzania, Mozambique and more recently also in Namibia (De Clercq et al., 2012; De Matos et al., 2009; Lynen et al., 2008; Nyangiwe et al., 2013a; Nyangiwe et al., 2013b). In Zimbabwe, Mason and Norval (1980) reported that the exotic R. microplus was displacing the autochthonous Rhipicephalus decoloratus in the eastern parts of the country with unconfirmed reports suggesting that because of the 19801983 drought $R$. microplus could actually have disappeared from the country (Norval et al., 1992), while subsequent research revealed that $R$. microplus was still limited to the eastern and northern parts of the country (Katsande et al., 1996) and that it could periodically spread into the interior areas of Zimbabwe (Smeenk et al., 2000). It still remains to be seen whether R. microplus has established in the interior of the country and whether it has displaced the local $R$. decoloratus ticks. Therefore the present study was carried out with a view of 
gathering preliminary information and empirical evidence on the distribution of ticks in Zimbabwe in different ecological zones, with particular emphasis on the blue ticks $R$. microplus and R.decoloratus.

\section{Materials and Methods}

\section{Study area and Sampling}

A total of one hundred and twenty one dip tanks from 12 districts representative of the 5 ecological regions of Zimbabwe were randomly selected for the study (see Figure 1 and Table 1). Multi-stage sampling was done where the dip-tank, farm or homestead was the secondary sampling unit in a district and then individual animals were the primary sampling unit. For the secondary sampling unit, considerations were also taken for accessibility to the area and farmer willingness to participate in the research. At least 5 cattle which were tick infested were sampled at each locality and in some cases available sheep, goats or dogs were sampled. In all the cases an effort was made to sample all the predilection sites in order to get a representative idea of all the species present in the area.

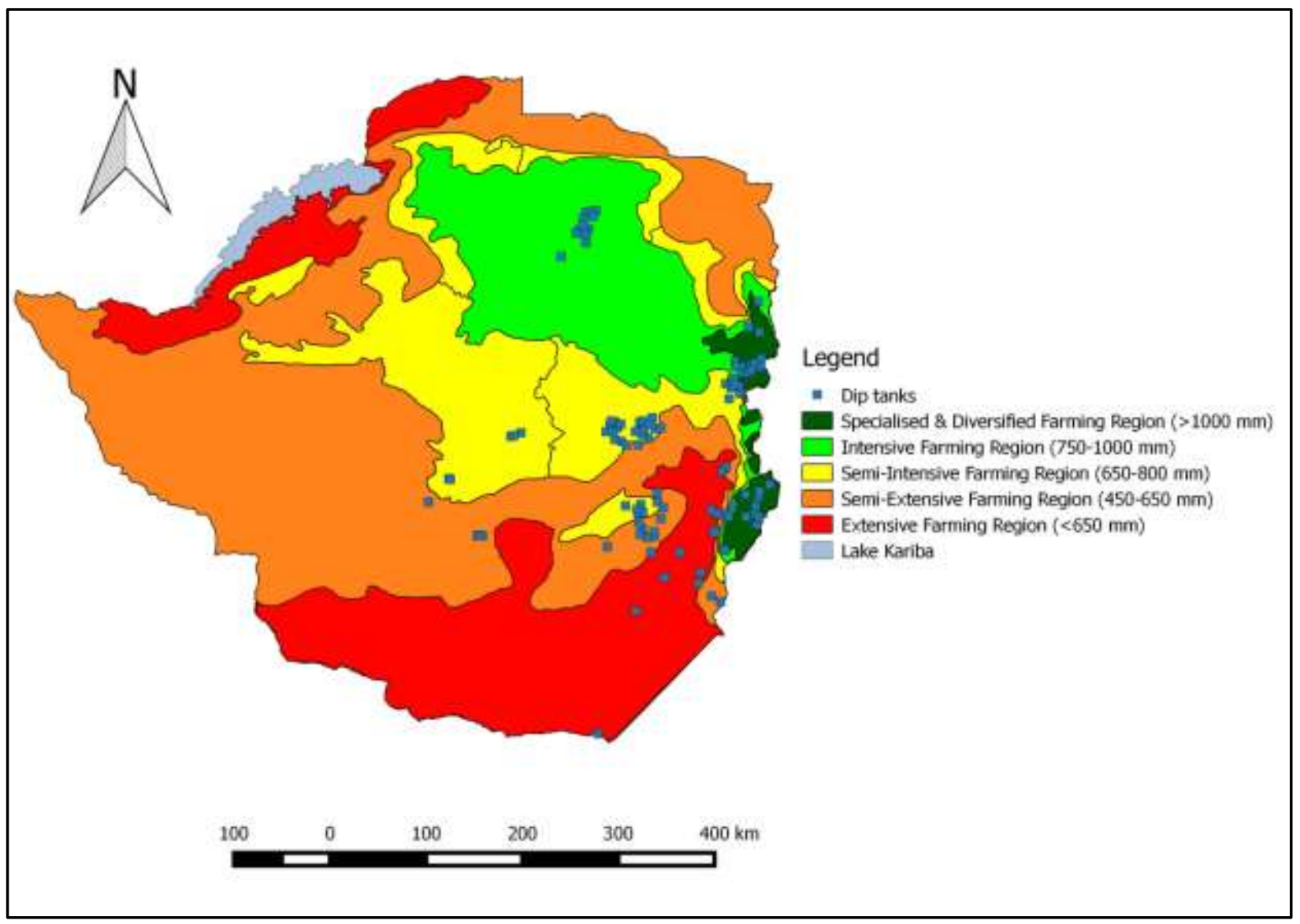

Figure 1: Map of Zimbabwe showing the ecological regions and the dip tanks at which ticks were collected 
Table 1: Characteristics of selected ecological regions of Zimbabwe and the number of dip tanks sampled

\begin{tabular}{|c|c|c|}
\hline Ecological region & Characteristics of region & $\begin{array}{c}\text { Number of dip-tanks sampled for } \\
\text { ticks }\end{array}$ \\
\hline 1 & $\begin{array}{l}<1000 \mathrm{~mm} \text { rainfall; mean annual temperature range of } \\
15- \\
18{ }^{\circ} \mathrm{C} \text {, mean minimum temperatures of } 10-12^{\circ} \mathrm{C} \\
\text { and mean maximum temperature range of } 19-23 \\
{ }^{\circ} \mathrm{C} \text {; tea, coffee, plantation farming, macadamia, fruits, } \\
\text { intensive livestock production. }\end{array}$ & 30 \\
\hline 2 & $\begin{array}{l}750-100 \mathrm{~mm} \text { rainfall; mean maximum temperature range of } \\
19-23{ }^{\circ} \mathrm{C} \text {, mean minimum temperature range of } 10-13{ }^{\circ} \mathrm{C} \\
\text { and mean annual temperature range of } 16-19{ }^{\circ} \mathrm{C} \text {; intensive } \\
\text { crop and livestock production. }\end{array}$ & 25 \\
\hline 3 & $\begin{array}{l}650-800 \mathrm{~mm} \text { of rainfall; mean maximum temperature range } \\
\text { of } \\
23-26{ }^{\circ} \mathrm{C} \text {, mean minimum temperature range of } 11-15^{\circ} \mathrm{C} \\
\text { and mean annual temperature range of } 18-22{ }^{\circ} \mathrm{C} \text {; severe } \\
\text { mid-summer droughts but maize, tobacco, cotton and other } \\
\text { cash crops grown }\end{array}$ & 37 \\
\hline 4 & $\begin{array}{l}650-800 \mathrm{~mm} \text { of rainfall; mean minimum temperature range } \\
\text { of } 11- \\
20{ }^{\circ} \mathrm{C} \text {, mean maximum temperature range of } 19-26 \\
{ }^{\circ} \mathrm{C} \text { and a mean annual temperature range of } 18-24 \\
{ }^{\circ} \mathrm{C} \text {; livestock and drought resistant crop production }\end{array}$ & 16 \\
\hline 5 & $\begin{array}{l}<450 \mathrm{~mm} \text { rainfall; mean annual temperature range of } 21-25 \\
{ }^{\circ} \mathrm{C} \text {, mean maximum temperature range of } 26-32{ }^{\circ} \mathrm{C} \text { and } \\
\text { mean minimum temperature range of } 14-18{ }^{\circ} \mathrm{C} \text {; supports } \\
\text { extensive cattle or game protection }\end{array}$ & 13 \\
\hline
\end{tabular}




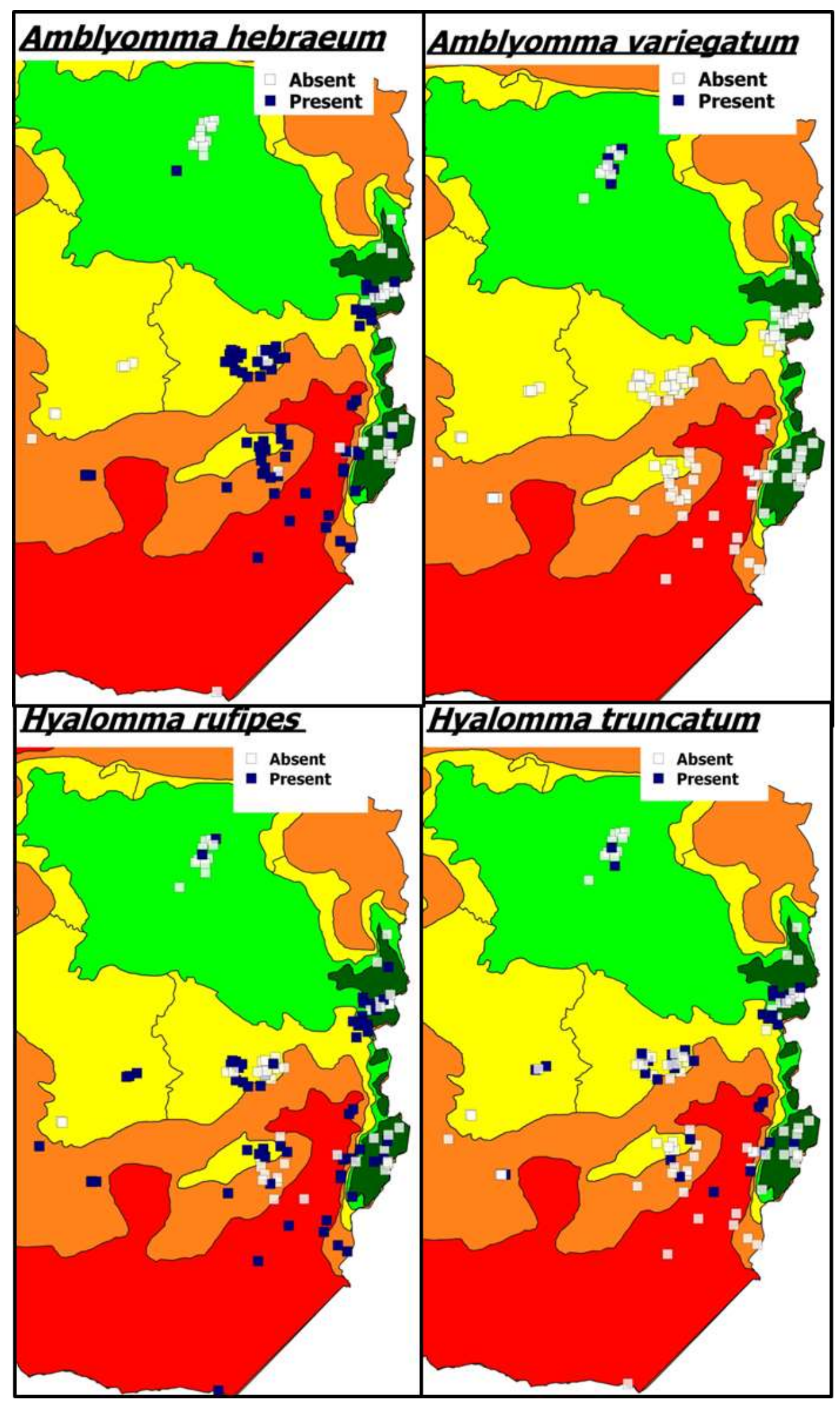

Figure 2: Ecological distribution of A. hebraeum, A. Variegatum, H. rufipes and H. truncatum 


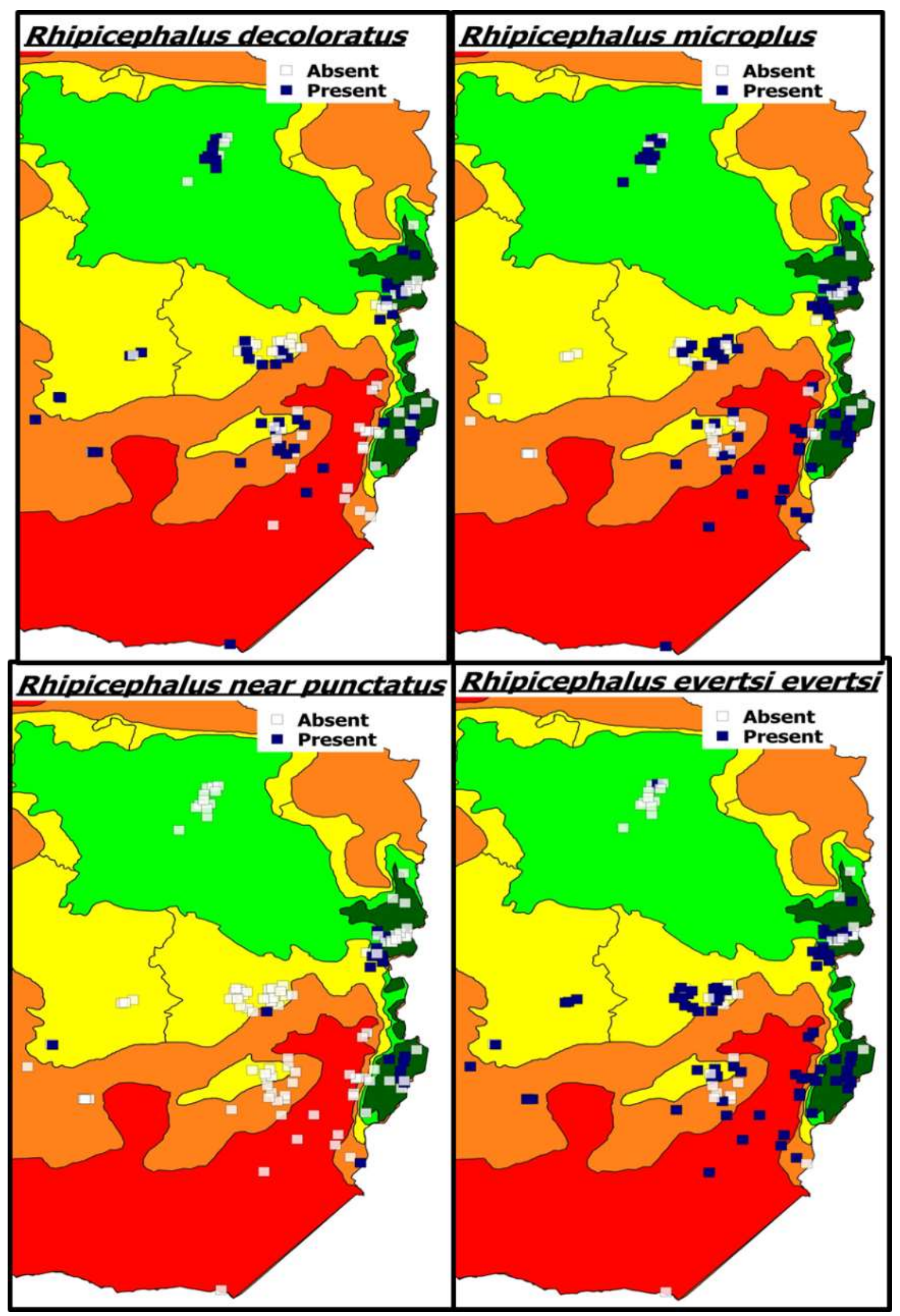

Figure 3: Ecological distribution of $R$. decoloratus, R. microplus, $R$. (near) punctatus and $R$. evertsi evertsi 


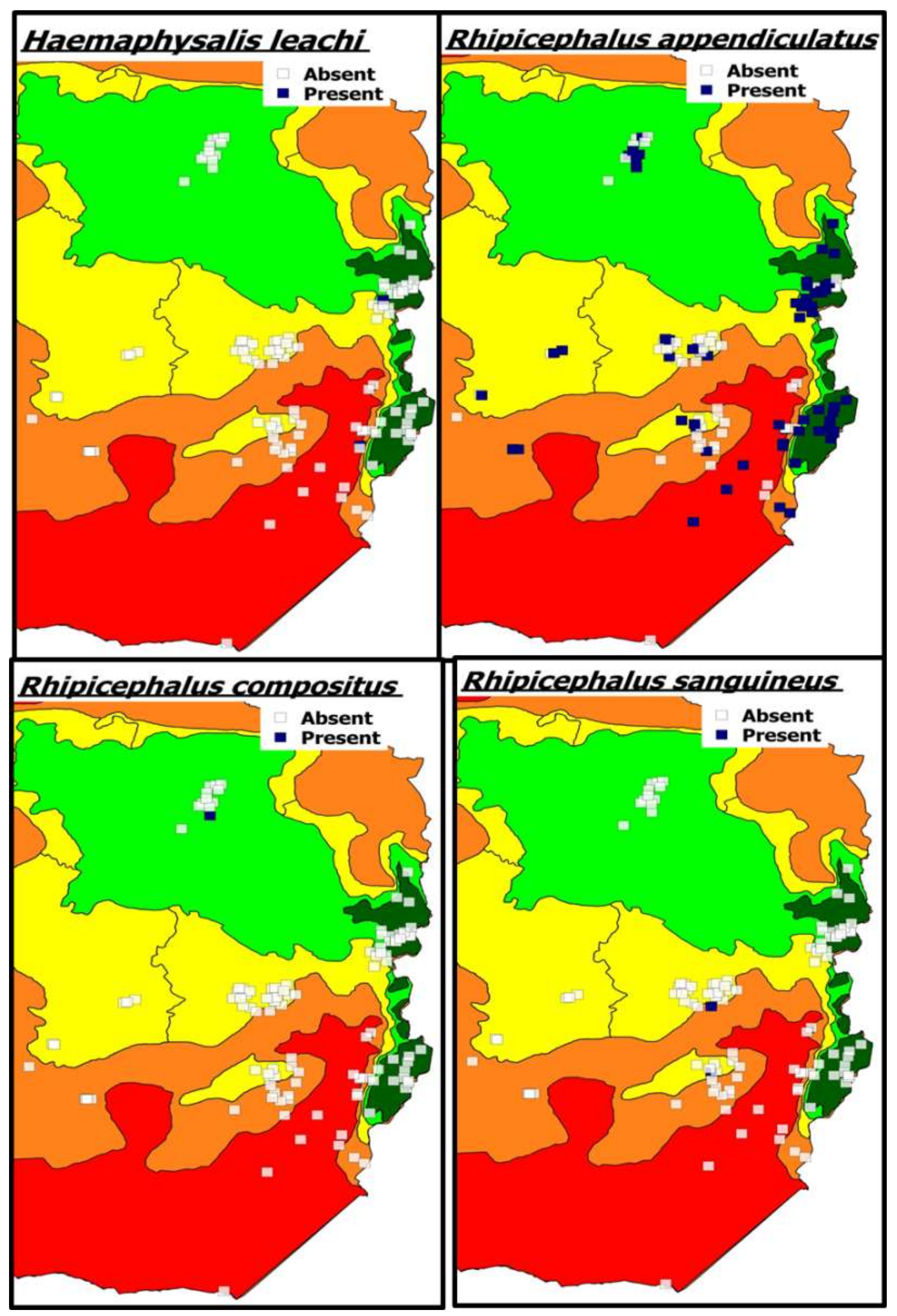

Figure 4: Ecological distribution of H. leachi, R. appendiculatus, R. compositus and R. sanguineus 


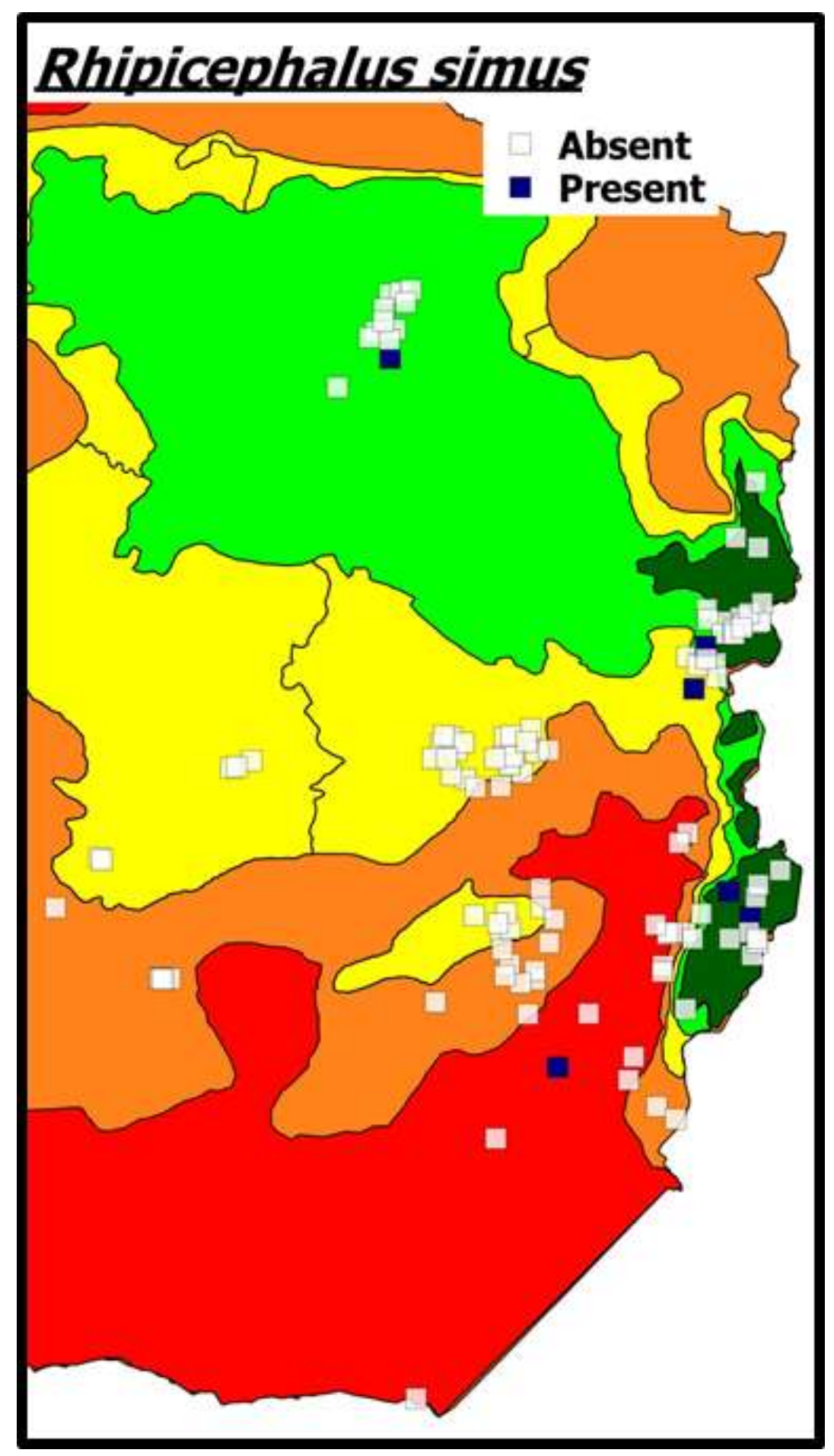

Figure 5: Ecological distribution of R. simus

The ticks were collected and preserved in $70 \%$ ethanol and morphological identification was done at the Institute of Tropical Medicine in Antwerp, Belgium. Approval was obtained from the Federal Agency for the Safety of the Food Chain (FASFC) to import the ticks to Belgium (M. Madder/ 06052014ZIM/U92040) which 
were then stored at the Institute of Tropical Medicine (ITM). Identification was done using morphological keys (Walker et al., 2003; Walker et al., 2000) and a stereo microscope at x 80 magnification; for the identification of the Boophilus ticks also a compound microscope was used. The identity of the Boophilus ticks was further confirmed by molecular work using PCR-RFLP with amplification of the ITS2 ribosomal gene region (Lempereur et al., 2010) and Cox 1 mitochondrial gene using the protocol described by Sungirai (2012). Twenty morphologically identified Boophilus ticks (4 R. decoloratus and 16 R.microplus) from different geographical areas had their identification confirmed by PCR-RFLP, while three Boophilus ticks identified as hybrids due to the presence of the protuberance bearing setae on the first segment of the palps despite the $4 \times 4$ dentition on the hypostome had their status confirmed as well by PCR-RFLP.

\section{Data analysis}

For each tick identified, data on the dip tank / farm name, GPS co-ordinates, district, and province were entered into MS Excel and exported to SPSS version 21 for descriptive analysis.

\section{Results}

\section{Tick identification}

In total 7,657 adult ticks were collected during the entire study period. The distribution of the tick species in different ecological regions is shown in Figures 1-5. A total of 13 tick species were identified and 8 of these were found in all the ecological zones of Zimbabwe (Amblyomma hebraeum, R. microplus, R. decoloratus, Hyalomma truncatum, Hyalomma rufipes, Rhipicephalus (near) punctatus and Rhipicephalus evertsi evertsi). Rhipicephalus microplus, Rhipicephalus appendiculatus and Rhipicephalus evertsi evertsi pre-dominated in ecological region 1, while $R$. microplus and $R$. appendiculatus dominated in region 2. Amblyomma hebraeum, Rhipicephalus evertsi evertsi, Rhipicephalus decoloratus, Hyalomma truncatum and Hyalomma rufipes predominated in ecological regions 3,4 and 5. An interesting observation was the high prevalence of $R$. microplus in ecological region 3 and the fact that it was collected at all the dip tanks sampled in ecological region 5. Amblyomma variegatum and Rhipicephalus compositus were only collected in ecological region 2 . Whenever dogs were sampled, the Haemaphysalis leachi group and Rhipicephalus sanguineus were the dominant species.

Table 2 shows the prevalence of the tick species collected in the study. Amblyomma hebraeum had the highest prevalence followed by $R$. microplus and R. appendiculatus whilst $R$. compositus had the lowest prevalence. 
Table 2: Prevalence (95\% confidence intervals (C.I) of tick species across the sampled dip tanks

Rhipicephalus simus

\section{PCR-RFLP}

The results of the PCR confirmed fifteen of the sixteen ticks (94\%) supposedly identified as R. microplus while four out five $R$. decoloratus ticks were confirmed as such. Only two ticks had been incorrectly diagnosed as $R$. 
microplus (1) and $R$. decoloratus (1). The ticks which had been identified as hybrids were actually pure $R$. microplus ticks both on ITS2 and Cox 1 amplification.

\section{Discussion}

The distribution of ticks is influenced by the distribution of their hosts and environmental factors (Norval, 1983). The movement of animals carries ticks to areas where they were not known to occur but it is the environmental conditions, and in particular climate, that will lead to the establishment of those tick species (Cumming, 1999). In Zimbabwe, the land reform programme has brought about changes in land ownership structure and as a consequence there have been migrations of farmers together with their livestock. This has led to movement of ticks to other regions. However, this proposition is still anecdotal as research which documents the present distribution of ticks in Zimbabwe is lacking. What is important to note is the identification of $A$. hebraeum in the eastern parts of the country, a region characterized by high rainfall and low-medium temperatures. According to Norval (1983), low-medium temperatures are not suitable for the development of the larval and nymphal stages of the tick and its presence in the east of Zimbabwe is therefore of significant importance. Traditionally, the distribution of A. hebraeum has been limited to the southern parts of the country since this tick was introduced from South Africa (Norval, 1983), but over the years the tick has been spreading upwards especially to the eastern parts of the country (Peter et al., 1998). Farmers and Veterinary Extension Agents interviewed in this study during tick collections in the Eastern Highlands of Zimbabwe indicated that this tick used not to be found in this region but was now becoming a problem to livestock health. The continued recording of A. hebraeum in the eastern parts of the country could mean that the tick has established in this region despite the adverse climatic conditions and the absence of alternative hosts such as the wild ungulates. On the other hand, A. variegatum was found only in the northern parts of Zimbabwe. Traditionally, $A$. variegatum has been restricted to the northwestern parts of the country and to areas along the eastern border with Mozambique in the Burma Valley (Hove et al., 2008; Norval, 1983; Peter et al., 1998). In this study, the tick was found in the Mazowe area which is located in the northern central parts of the country and this indicates movement of the tick, especially when considering previous reports on the distribution of the tick which showed the absence of the tick in the area (Peter et al., 1998). In addition, A. variegatum was not found in the eastern parts of the country where it was recorded by Peter et al. (1998). This could be indicative of interspecific competition with A. hebraeum, which could have displaced the former from the area. Norval (1983) reported that interspecific competition existed between the two species although they could share ecologically similar 
habitats. This could also suggest that there are areas where these two species dominate each other as it has been observed in the western and northern parts of Zimbabwe. In this region A. variegatum seemed to be the dominating species whilst from this study it is hypothesized that while this is true, A. hebraeum seems to predominate in the southern low-veld and the eastern highlands of the country.

The relationship between $R$. microplus and $R$. decoloratus has been extensively studied in other countries (De Clercq et al., 2012; Estrada-Peña et al., 2006; Lynen et al., 2008; Nyangiwe et al., 2013a; Tonnesen et al., 2004). It has been observed that due to its high reproductive capacity, shorter life cycle and faster development of resistance to acaricides, Rhipicephalus microplus is a highly invasive tick and tends to displace $R$. decoloratus in areas with a favorable warm and humid climate (De Clercq et al., 2012). However, there is a parapatric boundary that exists between the two species such that $R$. microplus fails to displace $R$. decoloratus in very dry and cold environments. In Zimbabwe the origins of $R$. microplus is thought to have been through livestock movements from Mozambique (Norval et al., 1983) while $R$. decoloratus is autochthonous to the country. The displacement of $R$. decoloratus by $R$. microplus was first reported by Norval et al. (1983) and this is said to have occurred in the north-eastern parts of the country with isolated incidents in the western areas. However, the same authors suggested that because of the 1980-1983 drought, $R$. microplus had been wiped out of the country. Successive studies have indicated that the tick is still present in the country (Katsande et al., 1999; Katsande et al., 1996; Smeenk et al., 2000) though this has been suggested to be due to periodic invasions from Mozambique. In the present study the prevalence of $R$. microplus was slightly higher than that of $R$. decoloratus in the sampled sites. Both species co-existed in $21 \%$ of the study sites, with either species dominating in $46 \%$ of those sites; $R$. microplus was the only blue tick in $28 \%$ of the sites while $R$. decoloratus was the only tick in $24 \%$ of the sites. This could suggest that unlike in other countries there has not been a complete displacement of $R$. decoloratus by $R$. microplus in Zimbabwe. What is also noteworthy is the presence of R. microplus in the interior of the country, suggesting that the tick could be spreading inwards. However more surveillance in these areas is needed to substantiate the above claims. The $R$. microplus ticks which had been found in unusual areas were confirmed as such by PCR-RFLP cementing the assertion that indeed $R$. microplus might be spreading into the interior of the country. The $R$. microplus ticks that had a hybrid morphology proved to be true $R$. microplus both upon ITS2 and Cox 1 amplification, which could be due to phenotypic variation that might occur in individuals of the same species. The other two ticks could have been incorrectly diagnosed due to the damaged mouth parts complicating morphological identification. 
Rhipicephalus evertsi evertsi was the most common tick in this study. Its distribution was fairly constant in all the ecological regions of Zimbabwe. It has been reported that $R$. evertsi evertsi tolerates a wide range of climatic conditions (Walker et al., 2000) and is widely distributed and common on livestock throughout much of Africa (Spickett et al., 2011). Similar results on the widespread distribution of $R$. evertsi evertsi in Zimbabwe were also reported by Hove et al. (2008) and Ndhlovu et al. (2009). Rhipicephalus appendiculatus was found in all the ecological regions of the country although it was most prevalent in ecological regions 1,2 and 5 . This tick species is reportedly widely distributed in the cooler and moist eastern parts of Zimbabwe as well as its southern parts (Norval et al., 1982a) which was confirmed in this study. Ecological region 5 has been deemed unsuitable for R. appendiculatus through modelling studies (Norval and Perry, 1990), but in this study the tick species were collected in the low-veld largely because ticks can and do become established in areas that are deemed to be unsuitable for their development (Norval and Perry, 1990). Other species of the Rhipicephalus genus found in this study are Rhipicephalus (near) punctatus, Rhipicephalus simus, Rhipicephalus compositus and Rhipicephalus sanguineus. Rhipicephalus (near) punctatus has been described as one of the lesser known Rhipicephalus species in Zimbabwe (Norval, 1985) and has been reported to have a wide distribution being found in both high and low rainfall areas (Walker et al., 2000). Rhipicephalus (near) punctatus formerly in the Rhipicephalus warbutonni group (Walker et al. 2000) is a variant of $R$. punctatus although it has light punctations and has been reported in southern western Angola and in the north of Mozambique (Horak et al., 2009), eastern Zambia (Berkvens et al., 1998) as well as some parts of Zimbabwe (Hove et al., 2008). This tick has been reported to cause paralysis in animals especially goats (Fourie and Horak, 2000). In this study the specimens of $R$. (near) punctatus were found in all the ecological regions although it was most common in regions 1 and 2 with high rainfall. Hove et al. (2008) also found the species being abundantly present on sheep and goats in areas located in ecological region 3. Rhipicephalus simus was found in ecological region 1, 2 and 5. Although it is said to be widely distributed (Norval and Mason, 1981), it is not common to find large number of ticks of the latter species on the animals, especially in the case of the domestic ruminants (Hove et al., 2008); hence this could have led to the tick not being found in other regions. The findings of $R$. compositus in this study do agree with the records of Walker et al. (2000) where the tick was collected in the Mazowe area, although the tick species is expected to be found in the northern and eastern parts of the country as well (Norval and Tebele, 1984). The dog ticks Rhipicephalus sanguineus and Haemaphysalis leachi group were collected whenever dogs were sampled. However, since dogs were not consistently sampled in this study, their prevalence was low, although these species are expected to occur throughout Zimbabwe (Norval, 1984; Norval et al., 
1982b). Hyalomma species are very common particularly in the drier parts of southern Africa (Walker, 1991), in this study the prevalence of $H$. rufipes was significantly higher than that of $H$. truncatum (confidence intervals of their prevalence do not overlap). Previous studies have shown that H. truncatum has a widespread distribution in Zimbabwe as compared to H. rufipes (Norval, 1982, Hove et al., 2008); this could not be observed in this study mainly because of the tendency of this tick to attach to the tail switch which is mostly overlooked during sampling, such observations were also made by Spickett et al. (2011). It is also noteworthy, however, that $H$. rufipes was found in the central and north central part of the country which indicated movement of this tick especially when looking at past published records. There is need to investigate this further.

\section{Conclusion}

This study has generated physical evidence to anecdotal views on tick migrations in Zimbabwe, especially for the Amblyomma ticks A. hebraeum and A. variegatum as well as the Boophilus ticks $R$. decoloratus and $R$. microplus which are important vectors for the diseases of socio-economic importance in the livestock industry of the country. There is still need for more monitoring to determine if indeed these tick species have established in these areas and to investigate the ecological relationships between the competing species.

\section{Acknowledgements}

The authors would like to thank the Belgian Department for Development Co-operation for the financial support which made this study to be possible. The Deputy Director-Research and Diagnostic Services of the Department of Veterinary Services Zimbabwe Dr. P.V. Makaya is acknowledged for the permission to do this research. We are also grateful to the provincial and district government veterinary officers as well as animal health inspectors for availing their staff to assist in tick collections.

Conflict of Interest

The authors declare that there is no conflict of interest in this study

\section{Reference List}

Berkvens, D.L., Geysen, D.M., Chaka, G., Madder, M., Brandt, J.R., 1998. A survey of the ixodid ticks parasitising cattle in the Eastern province of Zambia. Med.Vet. Entomol. 12, 234-240. 
Cumming, G.S., 1999. Host distributions do not limit the species ranges of most African ticks (Acari: Ixodida). Bull. Entomol. Res. 89, 303-327.

De Clercq, E.M., Vanwambeke, S.O., Sungirai, M., Adehan, S., Lokossou, R., Madder, M., 2012. Geographic distribution of the invasive cattle tick Rhipicephalus microplus, a country-wide survey in Benin. Exp. Appl. Acarol. 58, 441-452.

De Matos, C., Sitoe, C., Neves, L., Nothling, J.O., Horak, I.G., 2009. The comparative prevalence of five ixodid tick species infesting cattle and goats in Maputo Province, Mozambique. Onderstepoort. J. Vet.Res 76, 201-208.

Estrada-Peña, A., Garcia, Z., Sànchez, H.F., 2006. The distribution and ecological preferences of Boophilus microplus (Acari: Ixodidae) in Mexico. Exp. Appl. Acarol. 38, 307-316.

Fourie, L.J., Horak, I.G., 2000. Status of Dorper sheep as hosts of ectoparasites. Small Rumin. Res. 36, 159-164.

Horak, I.G., Nyangiwe, N., De, M.C., Neves, L., 2009. Species composition and geographic distribution of ticks infesting cattle, goats and dogs in a temperate and in a subtropical region of south-east Africa. Onderstepoort. J. Vet. Res. 76, 263-276

Hove, T., Mukandi, R., Bere, M., Horak, I.G., Latif, A.A., 2008. Ixodid ticks infesting domestic goats in communal land areas of Zimbabwe. J. S. Afr. Vet. Assoc. 79, 116-120.

Jongejan, F., Uilenberg, G., 2004. The global importance of ticks. Parasitology 129 Suppl, S3-14.

Katsande, T.C., More, S.J., Bock, R.E., Mabikacheche, L., Molloy, J.B., Ncube, C., 1999. A serological survey of bovine babesiosis in northern and eastern Zimbabwe. Onderstepoort. J. Vet. Res. 66, 255-263.

Katsande, T.S., Mazhowu Turton, J.A., Munodzana, D., 1996. Babesia bovis case reports and the current distribution of Boophilus microplus in Zimbabwe. Zimb Vet J 27, 33-36.

Léger, E., Vourc'h, G., Vial, L., Chevillon, C., McCoy, K.D., 2013. Changing distributions of ticks: causes and consequences. Exp. Appl. Acarol. 59, 219-244.

Lempereur, L., Geysen, D., Madder, M., 2010. Development and validation of a PCR $\square$ RFLP test to identify African Rhipicephalus (Boophilus) ticks. Act. Trop. 114, 55-58.

Lynen, G., Zeman, P., Bakuname, C., Di, G.G., Mtui, P., Sanka, P., Jongejan, F., 2008. Shifts in the distributional ranges of Boophilus ticks in Tanzania: evidence that a parapatric boundary between Boophilus microplus and B. decoloratus follows climate gradients. Exp. Appl. Acarol. 44, 147-164.

Mason, C.A., Norval, R.A.I., 1980. The ticks of Zimbabwe. I. The genus Boophilus. Zimb Vet J 11, 36-43. 
Ndhlovu, D.N., Makaya, P.V., Penzhorn, B.L., 2009. Tick infestation, and udder and teat damage in selected cattle herds of Matabeleland South, Zimbabwe. Onderstepoort. J. Vet. Res 76, 235-248.

Norval, R.A.I., 1982. The ticks of Zimbabwe. IV. The genus Hyalomma. Zimb Vet J 13, 2-10.

Norval, R.A.I., 1983. The ticks of Zimbabwe. VII. The genus Amblyomma. Zimb Vet J 14, 3-6.

Norval, R.A.I., 1984. The ticks of Zimbabwe. IX. Haemaphysalis leachi and Haemaphysalis spinulosa. Zimb Vet J 15, 9-17.

Norval, R.A.I., 1985. The ticks of Zimbabwe. XII. The lesser known Rhipicephalus species. Zimb Vet J 16, 37-43.

Norval, R.A.I., Mason, C.A., 1981. The ticks of Zimbabwe. II. The life cycle, distribution and hosts of Rhipicephalus simus Koch, 1844. Zimb Vet J 12, 2-9.

Norval, R.A., Perry, B.D., 1990. Introduction, spread and subsequent disappearance of the brown ear-tick, Rhipicephalus appendiculatus, from the southern lowveld of Zimbabwe. Exp. Appl. Acarol. 9, 103-111.

Norval, R.A.I., Tebele, N., 1984. The ticks of Zimbabwe. VIII. Rhipicephalus compositus. Zimb Vet J 15, 3-8.

Norval, R.A.I., Daillecourt, T., Pegram, R.G., 1982b. The ticks of Zimbabwe. VI. The Rhipicephalus sanguineus group. Zimb Vet J 13, 38-46.

Norval, R.A., Fivaz, B.H., Lawrence, J.A., Daillecourt, T., 1983. Epidemiology of tick-borne diseases of cattle in Zimbabwe. I. Babesiosis. Trop. Anim Health Prod. 15, 87-94.

Norval, R.A., Perry, B.D., Hargreaves, S.K., 1992. Tick and tick-borne disease control in Zimbabwe: what might the future hold. Zimb Vet J 23, 1-15.

Norval, R.A., Walker, J.B., Colborne, J., 1982a. The ecology of Rhipicephalus zambeziensis and Rhipicephalus appendiculatus (Acarina, Ixodidae) with particular reference to Zimbabwe. Onderstepoort. J. Vet. Res 49, 181190.

Nyangiwe, N., Harrison, A., Horak, I.G., 2013a. Displacement of Rhipicephalus decoloratus by Rhipicephalus microplus (Acari: Ixodidae) in the Eastern Cape Province, South Africa. Exp. Appl. Acarol 61, 371-82

Nyangiwe, N., Matthee, C., Horak, I., Matthee, S., 2013b. First record of the pantropical blue tick Rhipicephalus microplus in Namibia. Exp. Appl. Acarol. 61, 503-507. 
Peter, T.F., Perry, B.D., O'Callaghan, C.J., Medley, G.F., Shumba, W., Madzima, W., Burridge, M.J., Mahan, S.M., 1998. Distributions of the vectors of heartwater, Amblyomma hebraeum and Amblyomma variegatum (Acari: Ixodidae), in Zimbabwe. Exp. Appl. Acarol. 22, 725-740.

Smeenk, I., Kelly, P.J., Wray, K., Musuka, G., Trees, A.J., Jongejan, F., 2000. Babesia bovis and B. bigemina DNA detected in cattle and ticks from Zimbabwe by polymerase chain reaction. J. S. Afr. Vet Assoc. 71, 21-24.

Spickett, A.M., Heyne, I.H., Williams, R., 2011. Survey of the livestock ticks of the North West province, South Africa. Onderstepoort. J. Vet. Res. 78, 1-12.

Sungirai, M., 2012. Identification of the four Rhipicephalus(Boophilus) tick species and their hybrids from Benin: morphology versus genetics. MSc Dissertation. Institute of Tropical Medicine.

Tonnesen, M.H., Penzhorn, B.L., Bryson, N.R., Stoltsz, W.H., Masibigiri, T., 2004. Displacement of Boophilus decoloratus by Boophilus microplus in the Soutpansberg region, Limpopo Province, South Africa. Exp. Appl. Acarol. 32, 199208.

Walker, A.R., Bouattour, A., Camicas, L., Estrada-Peña, A., Horak, I.G., Latif, A.A., Pegram, P.G., Preston, P.M., 2003. Ticks of Domestic Animals in Africa: a Guide to Identification of Species. Bioscience Reports, Edinburgh.

Walker, J.B., 1991. A review of the ixodid ticks (Acari, Ixodidae) occurring in southern Africa. Onderstepoort. J.Vet. Res. $58,81-105$.

Walker, J.B., Keirans, J.E., Horak, I.G., 2000. The genus Rhipicephalus (Acari, Ixodidae): a guide to the brown ticks of the world. Cambridge University Press. 